\title{
Interação Entre Competências Gerenciais e Fatores do Ambiente de Trabalho: um Estudo com Gestores do Setor de Comércio de Santana do Livramento/RS
}

\section{Interaction Between Managerial Competences and the Workplace Factors: a Study With Commerce Sector Managers of Santana do Livramento/RS}

\author{
Marilia Vaz dos Santos ${ }^{\mathrm{a}}$; Carolina Freddo Fleck ${ }^{\mathrm{b}}$; Márcia Vanessah Pacheco Abbondanza*c \\ anniversidade Federal do Pampa, Curso de Administração. RS, Brasil \\ bUniversidade Federal do Pampa. RS, Brasil \\ 'Universidade Federal do Pampa, Programa de Pós-Graduação Stricto Sensu em Administração. RS, Brasil \\ *E-mail: marciaabbondanz@gmail.com
}

\begin{abstract}
Resumo
As organizações sofrem influências tanto do ambiente externo quanto do interno, de forma que cada vez mais as competências do profissional se tornam elementos importantes nesse contexto. Sendo assim, o ambiente de trabalho passa a ser visto como elemento fundamental para potencializar ou não o desempenho do profissional. O objetivo deste estudo é identificar em gestores de empresas do setor de comércio, a relação entre competências gerenciais e o seu desenvolvimento a partir das exigências do ambiente. O modelo teórico adotado foi o de Fleury e Fleury (2001). A abordagem é qualitativa, sendo uma pesquisa descritiva do qual se utilizou um roteiro de uma entrevista semiestruturada aplicado a oito gestores do setor de comércio de Santana do Livramento/RS. Identificou-se que os gestores possuíam as competências de "saber agir" e "saber assumir responsabilidades" bastante desenvolvidas antes de assumirem suas atuais posições no mercado de trabalho. Entre as competências mais desenvolvidas pelas variáveis do ambiente de trabalho estão: "saber comunicar", "saber mobilizar" e "ter visão estratégica". O estudo não considera o desenvolvimento das competências como estático no tempo, apenas se buscou verificar se houve a possibilidade de distinguir quais dessas foram mais desenvolvidas a partir do momento em que os entrevistados assumiram seus atuais cargos. A dinâmica do aprender e desenvolver é constante.
\end{abstract}

Palavras-chave: Competências Gerenciais. Ambiente de Trabalho. Gestão.

\begin{abstract}
Organizations provide influences from both external and internal environment, in a way that professional competences have increasingly become important elements in this context. Thus, the workplace is seen as a fundamental element to potentialize or not the professional performance. The purpose of this study is to identify in managers of companies in the commerce sector, the relationship between managerial competences and their development based on the environment requirements. The theoric model adopted was that of Fleury and Fleury (2001). The approach is qualitative, being a descriptive research which used a script of a semi-structured interview applied to eight managers of the commerce sector in Santana do Livramento/RS. It was identified that the managers had the competences of "know how to act" and "know how to assume responsibilities" well developed before assuming their current positions in the job market. Among the most developed competences by the variables of the work environment are: "know how to communicate", "know how to mobilize" and "having a strategic vision". The study does not consider the development of competences to be static over time, it only sought to verify whether there was a possibility to distinguish which ones were more developed from the moment the interviewees assumed their current positions. The dynamics of learning and developing is constant.
\end{abstract}

Keywords: Managerial Competences. Workplace. Management.

\section{Introdução}

A influência do ambiente sobre uma organização abrange todos os seus aspectos. Fatores como concorrência, governo, clientes e fornecedores fazem parte do Universo tanto extrínseco quanto intrínseco de uma organizção. De acordo com Dutra et al. (2001), tanto o ambiente interno quanto o externo pressionam cada vez mais as organizações a investir em desenvolvimento humano, e essas mesmas já perceberam isso como forma de adquirir vantagens competitivas no mercado. $\mathrm{O}$ ambiente, aliado às circunstâncias, passa a exigir do profissional certas atitudes que levam à tomada de decisões. Isso pode ocorrer tanto quando alguém é posto em um cargo gerencial, como também quando a liderança é informal.
Desde a década de 1970, há um crescente debate em Administração, incluindo a Psicologia Organizacional, na área de gestão de pessoas, sobre as competências das pessoas para o trabalho. De acordo com Fleury e Fleury (2001), há diferentes instâncias de compreensão e são essas: as competências dos países, que incluem os sistemas educacionais; as competências organizacionais, as chamadas core competences, e em nível individual, as competências individuais. Há autores que apontam que as competências individuais são reveladas quando as pessoas agem diante de situações profissionais com as quais se deparam (BRANDÃO; BORGES-ANDRADE, 2007).

Sendo assim, o ponto de partida para tratar de competências gerenciais não é o indivíduo considerado isoladamente. As 
competências da organização, as chamadas competências essenciais, que se apresentam como o resultado da sinergia entre as competências de todos os profissionais envolvidos, podem ser importantes pontos de referência. E a partir destas referências se pode considerar que entre as competências profissionais individuais, as gerenciais se mostram relevantes para os estudos na área de gestão de pessoas, especialmente, pela demanda crescente e contínua que os fatores ambientais exercem sobre quem atua em cargos de gestão. Vários autores abordam a questão de trabalhar as competências como a gestão das mesmas e para as mesmas, pois o que se busca não é o desenho de um projeto do líder ideal, mas sim a aproximação e interação do perfil real do gestor com as pressões e oportunidades dinâmicas do ambiente de trabalho (DUTRA et al., 2001; FLEURY; FLEURY, 2001; BITENCOURT, 2004).

O cenário no qual os gestores deste estudo atuam é o município de Santana do Livramento, RS, Brasil. Esta cidade possui a peculiaridade de ser fronteira seca com a cidade de Rivera, no Uruguai, sendo cultural e economicamente interdependente de sua vizinha. Até a década de 1990, Santana do Livramento possuía uma economia pautada em latifúndios agrícolas, lanifícios e frigoríficos, mas com o declínio dessas atividades, o foco passou a ser o comércio de abastecimento popular (BRAGA; RIGATTI, 2009). Além disso, a cidade conta com serviços voltados ao ramo do turismo, já que o turismo por compras é bastante comum na fronteira, principalmente, em função dos free shops do lado uruguaio.

O presente estudo analisa a dinâmica das competências gerencias com as exigências do ambiente. Tendo em vista que o ambiente organizacional é dinâmico e permeado de demandas competitivas, não se deve ignorar que para manter uma empresa funcionando na atual configuração, seus profissionais devem ter habilidades que as favoreçam no mercado. E mesmo para as organizações sem fins lucrativos, a manutenção da imagem e a busca pelo alcance eficaz da visão institucional é um constante desafio. Entende-se importante conhecer quais competências gerenciais têm sido desenvolvidas nessas pessoas, já que a organização e as pessoas possuem um processo contínuo de troca de competências, a empresa transfere seu patrimônio para as pessoas, preparando-as para enfrentar novas situações ao passo que as pessoas transferem para a organização o seu aprendizado, injetando sua capacidade individual (DUTRA et al., 2001). Conhecer as habilidades dos gestores e comparar com os conceitos de competências gerenciais é interessante para identificar líderes, que independente de possuir ou não, a qualificação para tal, desempenham na prática esse papel.

$\mathrm{O}$ ambiente de trabalho passa a ser visto como elemento fundamental para potencializar ou não os resultados do desempenho do profissional, e dessa forma se considerou pertinente analisar como os elementos ambientais influenciam no trabalho de gestores e este estudo contribui para tal análise, uma vez que seu objetivo foi identificar em gestores do comércio de Santana do Livramento/RS, a relação entre competências gerenciais e o seu desenvolvimento a partir das exigências do ambiente.

\section{Material e Métodos}

Este estudo é de abordagem qualitativa e caráter descritivo, pois se pretendeu aplicar o modelo teórico de Fleury e Fleury (2001), considerando que a teoria das competências é bastante consolidada, não houve também a intenção de generalizar os resultados, mas sim, de aprofundar o fenômeno com um pequeno grupo de respondentes.

O método escolhido foi o de estudo narrativo, sendo este um estudo qualitativo realizado com populações pequenas, concentrando-se mais na narrativa do tema estudado do que com os indivíduos em si (CRESWELL, 2014), nesse caso, o tema de competências gerenciais.

Como instrumento de coleta de dados se utilizou a entrevista, considerando esta como um instrumento que permite a interação entre pesquisador e entrevistado (OLIVEIRA, 2008). Dos tipos de entrevista se optou por um roteiro de questões semiestruturado, que segundo Hair et al. (2005, p. 163): "têm uma estrutura e orientações gerais, mas permitem muita flexibilidade para incluir perguntas nãoestruturadas". Dessa forma, no momento da entrevista, novas perguntas podem surgir de acordo com a necessidade de aprofundamento das informações, sem a obrigatoriedade de seguir um roteiro fechado.

Foram entrevistados homens e mulheres que atuam como gestores em organizações do comércio da cidade de Santana do Livramento/RS. Essas pessoas trabalham diariamente com tomada de decisões e atitudes estratégicas, além é claro, de tratar com clientes internos e externos à organização. A escolha por este local de pesquisa ocorreu pela proximidade das pesquisadoras com o mesmo e pela peculiaridade de ser um ambiente em que os gestores atuam em uma cidade de fronteira seca, recebendo constantemente clientes dos dois países. A fim de não revelar a identidade dos entrevistados se optou por diferenciá-los de acordo com as letras do alfabeto, de $\mathrm{A}$ a $\mathrm{H}$, totalizando oito entrevistados.

Em relação ao entrevistado $\mathrm{A}$, a sua entrevista também serviu como um pré-teste. De acordo com Oliveira (2008, p. 90): "Uma vez elaborado o questionário, é importante realizar um pré-teste e/ou sondagem para identificação de possíveis falhas quanto à redação das questões". Sendo assim, o pré-teste serve para identificar falhas relacionadas à possível imprecisão do instrumento de pesquisa e excesso de quantidade ou complexidade das questões. No presente estudo, o entrevistado A compreendeu todas as perguntas, não sendo preciso ajustar o roteiro para dar continuidade à pesquisa.

Todas as entrevistas ocorreram pessoal e individualmente, sendo gravadas por dispositivo móvel e, logo após, transcritas. O conteúdo das entrevistas foi analisado através da análise interpretativa, que segundo Severino (2017), toma uma 
posição própria a respeito das ideias enunciadas, e tem como o objetivo superar a estrita mensagem do texto. Dessa forma, apresenta-se a análise com um texto mais fluído, sempre relacionando às respostas dos entrevistados com o modelo proposto por Fleury e Fleury, presente no Quadro 1.

Quadro 1 - Competências do profissional

\begin{tabular}{|l|l|}
\hline Saber agir & $\begin{array}{l}\text { Saber o que e por que se faz. Saber julgar, } \\
\text { escolher, decidir. }\end{array}$ \\
\hline Saber mobilizar & $\begin{array}{l}\text { Saber mobilizar recursos de pessoas, } \\
\text { financeiros, materiais, criando sinergia } \\
\text { entre eles. }\end{array}$ \\
\hline Saber comunicar & $\begin{array}{l}\text { Compreender, processar, transmitir } \\
\text { informações e conhecimentos, } \\
\text { assegurando o entendimento da } \\
\text { mensagem pelos outros. }\end{array}$ \\
\hline Saber aprender & $\begin{array}{l}\text { Trabalhar o conhecimento e a } \\
\text { experiência. Rever modelos mentais. } \\
\text { Saber desenvolver-se e propiciar o } \\
\text { desenvolvimento dos outros. }\end{array}$ \\
\hline $\begin{array}{l}\text { Saber } \\
\text { comprometer-se }\end{array}$ & $\begin{array}{l}\text { Saber engajar-se e comprometer-se com } \\
\text { os objetivos da organização. }\end{array}$ \\
\hline $\begin{array}{l}\text { Saber assumir } \\
\text { responsabilidades }\end{array}$ & $\begin{array}{l}\text { Ser responsável, assumindo os riscos e as } \\
\text { consequências de suas ações, e ser, por } \\
\text { isso, reconhecido. }\end{array}$ \\
\hline $\begin{array}{l}\text { Ter visão } \\
\text { estratégica }\end{array}$ & $\begin{array}{l}\text { Conhecer e entender o negócio da } \\
\text { organização, seu ambiente, identificando } \\
\text { oportunidades, alternativas. }\end{array}$ \\
\hline Fonte: Fleury e Fleury (2001, p.22).
\end{tabular}

Devido a este modelo de sete competências de Fleury e Fleury $(2001 ; 2004)$ se encaixar em uma abordagem prática e dinâmica, esse é a base de identificação das competências apontadas por este estudo. Apresentam-se como competências individuais, mas se enquadram também no perfil de líderes nas organizações, os quais são o objeto deste estudo.

\section{Resultados e Discussão}

A teoria sobre competências é ampla e possui múltiplas facetas, o que propicia dinamismo para sua pesquisa e a noção, desde já, de que não há como criar uma conceituação estática e absoluta para essas. Fleury e Fleury (2001) relatam que o início do debate acerca de competências começou a partir de McClelland (1973), sob uma ótica individual, com a publicação de Testing for Competence rather than Intelligence. Segundo os autores, para McClelland (1973), a competência é uma característica subjacente relacionada a um desempenho superior ao realizar uma tarefa ou em viver uma situação.

Com o desenvolvimento das pesquisas ficaram evidentes duas vertentes principais de pensamento: a abordagem americana, desde a década de 1970, mais racionalista, que procura uma definição completa para o desempenho gerencial, e a abordagem europeia, que segue uma linha interpretativa, relacionando cultura da organização e o modelo de gestão aliado às competências (FLECK, 2008).

De acordo com Fleury e Fleury (2004), Richard Boyatzis (1982) contribuiu, significativamente, para os estudos americanos na década de 1980, identificando um conjunto de características e traços que definiriam um desempenho superior. É dessa perspectiva que as competências passam a ser vistas como um conjunto de conhecimentos, habilidades e atitudes, formando um estoque que a pessoa detém. Os melhores desempenhos, então, são vistos como fundamentados na inteligência e na personalidade do profissional. Assim, observou-se que a maioria dos autores americanos alinha competências à necessidade do cargo. Essa abordagem é considerada como uma roupagem mais moderna para gerir uma realidade organizacional fundada nos princípios do taylorismo-fordismo, porque a competência ainda permanece vinculada à qualificação e requisitos do cargo, o que não é suficiente para atender às demandas de uma organização complexa em um Mundo globalizado.

A corrente europeia, no entanto, formada especialmente por autores franceses, "associa a competência não a atributos ou qualificações da pessoa, mas sim as suas realizações em um dado contexto, ou seja, àquilo que o indivíduo produz ou realiza no trabalho" (DUTRA, 2004). Portanto, vai além da ideia de ser tão somente a bagagem, a qualificação que a pessoa traz, mas também o que ela é capaz de continuamente aprender e desenvolver. Conforme Fleury e Fleury (2001), os franceses estavam insatisfeitos com o descompasso entre as necessidades do Mundo do trabalho e o que era ensinado aos trabalhadores. $\mathrm{O}$ que se procurava era aproximar o ensino às necessidades reais das empresas, para aumentar eficazmente as qualificações dos trabalhadores e suas chances de se empregarem. O conceito de competências passa então a se inserir em novas áreas: do campo educacional para o das relações trabalhistas, avaliando as qualificações que os postos de trabalho demandam.

Na década de 1990, na literatura francesa, o conceito de competência pretendia ir além da noção de qualificação. Essa escola via as competências como algo dinâmico. Dessa forma, Zarifian (1999) elencou três pontos do Mundo do trabalho para amparar a necessidade de um modelo de competência para a gestão organizacional: i) evento - o que não ocorre de forma prevista e pode interferir no curso normal do sistema de produção; ii) comunicação - compreensão para com os outros e consigo, de forma a entrar de acordo com os objetivos da organização e o compartilhamento de normas comuns à gestão; iii) serviço - que envolve atendimento aos clientes externos e internos da organização.

A partir do momento em que se trabalha com o inesperado, que se considera a necessidade de mobilizar recursos, e já não há mais receita de bolo para resolver problemas se tem que o imprevisto faz parte do dia a dia e que "o trabalho não é mais o conjunto de tarefas associadas ao cargo, mas se torna o prolongamento direto da competência que o indivíduo mobiliza em face de uma situação profissional cada vez mais mutável e complexa" (FLEURY e FLEURY, 2004, p. 46).

Há também uma vertente integradora das duas correntes de pensamento, amparado por Gonczi (1999), a qual indica que 
a competência aborda atributos pessoais em seus diferentes contextos de utilização, como o ambiente de trabalho que a pessoa está inserida. Sendo assim, a competência se trata de uma gama de conhecimentos, de habilidades e de atitudes pertinentes para o exercício da atividade, bem como comportamentos adotados pela pessoa no trabalho e as realizações desses decorrentes (CARBONE et al., 2005).

Quanto às várias dimensões do conceito se pode pensar de uma maneira didática que há tipos diferentes de competências. São exemplos as chamadas competências técnicas e gerenciais (COCKERIL, 1994), e são realizadas de acordo com o papel ocupacional. As competências técnicas são relevantes para profissionais de áreas técnicas, de assessoramento ou operacionais, sem que haja formalmente o cargo de liderança, conforme Brandão et al. (2008).

Neste estudo, são focadas as competências gerenciais, que representam comportamentos oriundos dos cargos, assim como funções de supervisão e direção (GONCZI, 1999). Esses comportamentos esperados de um líder, portanto, são amparados por elementos que os sustentam e podem ser simples de exemplificar como cuidar bem da relação com clientes, pontualidade, respeito à hierarquia organizacional, ou seja, tudo aquilo que o gerente pode servir como um bom exemplo: os padrões comportamentais.

Diante das considerações teóricas expostas é interessante observar como ocorre a interação entre a dinâmica do trabalho e os conhecimentos, as habilidades e as atitudes do indivíduo. Segundo o modelo de Fleury e Fleury (2004, p. 48), estes elementos intrínsecos devem ser postos em prática para então se caracterizarem como competências:

A competência do indivíduo não é um estado, não se reduz a um conhecimento ou know how específico [...]. A nosso ver, a noção de competência aparece, assim, associada a verbos e expressões como: saber agir, mobilizar recursos, integrar saberes múltiplos e complexos, saber aprender, saber se engajar, assumir responsabilidades e ter visão estratégica. [...] observa-se que essas competências não são apenas conhecimentos ou habilidades, são conhecimentos ou habilidades em ação.

De acordo com Fleury e Fleury (2004), há diferentes níveis de competência que se formam na organização: as competências organizacionais se situam em um nível mais geral, nas unidades e funções. Entre estas há as competências essenciais que são básicas para a elaboração da estratégia competitiva. Essas competências, no entanto, são formadas a partir da combinação de recursos e de múltiplas competências no nível individual. As competências individuais somadas dão um resultado maior do que essas consideradas isoladamente, há então a presença de sinergia na dinâmica das competências no contexto organizacional (Ibid).

Fleury e Fleury (2001) apresentam seu conceito para competências como sendo um saber agir responsável e reconhecido pelos outros, que abrange mobilização, integração e transferência de conhecimentos, de recursos e de habilidades. Tudo isso agrega valor econômico à organização e valor social ao indivíduo.

As correntes teóricas que abordam competências individuais não distinguem, e talvez nunca logrem distinguir, as competências inatas aos indivíduos, as adquiridas através da observação e estudo e, em última instância, as que foram desenvolvidas pelas pressões do ambiente. Ao contrário, há vários estudiosos que afirmam que as competências são fruto de todos esses fatores associados e combinados, particulares a cada indivíduo. O que se constatou nos oito entrevistados foi que todos desenvolveram habilidades mediante as circunstâncias do trabalho.

\subsection{Entrevistado A}

A primeira nuance do que consiste o conjunto de competências do profissional de Fleury e Fleury (2001, p. 22), em relação ao saber agir, se desdobra em "saber o que e por que se faz. Saber julgar, escolher, decidir”. Esta foi, pela lógica adotada no trabalho, a primeira Unidade de Contexto abordada. Quanto a isso, o entrevistado demonstrou ter uma boa noção. Quando perguntado sobre seu cargo se foca em suas responsabilidades: sou responsável por fazer as compras da empresa, controlar o estoque dos produtos e fazer escala de serviço dos domingos e feriados.

O que chama a atenção é o fato de que quando perguntado se é parte de seu trabalho fazer a mediação na relação da empresa com seus fornecedores, na Unidade de Contexto sobre Saber Comunicar, ele destaca que sim e da seguinte forma: "Negociando com eles os melhores descontos e prazos para pagamento". Quando perguntado acerca da relação da empresa com os clientes, ele responde que participa também do atendimento a eles.

O trabalho com os fornecedores e as vendas aos clientes são atividades que demandam habilidades como poder de negociação, para ambos os atores envolvidos, e atendimento ao público. Tudo isso posto em prática logo após seu ingresso na empresa. Quando perguntado se com o seu conhecimento formal foi possível assumir o cargo, ele revela: "Apenas com conhecimento geral que eu tinha não, mas quando fui instruído e qualificado, sim".

Quando perguntado se precisou desenvolver novas habilidades:

Sim, e o principal foi aprender a fazer compras em grande quantidade tendo controle de não comprar demais nem de menos, sempre controlando o quanto está sendo vendido para saber o quanto comprar, sem deixar acumular muitos pagamentos num dia só.

Segundo Zarifian (2001), a competência é um entendimento prático de situações que se apoia em conhecimentos e os transforma na medida em que aumenta a diversidade nas situações. Saber lidar com tal diversidade e pôr os conhecimentos em prática é algo valioso e imprescindível para os líderes nas organizações, Fleck (2008, p. 26) comenta este conceito dizendo que ele parte do pressuposto de que:

[...] gerentes competentes utilizam seu conhecimento 
prévio, o saber; aliado ao ambiente no qual está inserida a organização, através de habilidades, que envolvem o saberfazer, que irão gerar a possibilidade de desenvolvimento de um bom trabalho e de uma imagem diante dos funcionários e da organização de acordo com suas atitudes.

Na Unidade de Contexto sobre Saber Aprender revela que não necessitou adotar novas tecnologias, mas destaca que sua educação formal foi útil também no tratamento com superiores "Sem dúvidas que sim. Na questão do tratamento com superiores, sempre mantendo o respeito e sabendo ouvir quando preciso mudar alguma atitude", o que aponta que ele já possuía características como disciplina, podendo ser uma característica oriunda dos anos de serviço militar.

Suas respostas em outras Unidades de Contexto revelam que ele compartilha com a equipe a responsabilidade pela imagem da empresa: "Tento mostrar que se a empresa estiver indo bem, nosso trabalho será bem-visto... e com isso teremos sempre boas referências". E tem aplicado suas ideias em relação à competitividade do negócio: "Sim, tenho aplicado, porque eu preciso 'vestir a camiseta', enquanto estiver na empresa eu devo me engajar para que a minha função não tenha ou tenha o mínimo de falhas possível e isso eu consigo aplicando ideias que visam melhorar o desempenho da minha função e também para aumentar a produtividade da empresa". Diante de tarefas importantes, afirma que procura fazer seu melhor, mas com naturalidade. Salles e Villardi (2017) apontaram que um fator importante para o desenvolvimento de competências é a atitude de pertencimento e de responsabilidade refletida na dedicação, o que corrobora com essa visão de "vestir a camiseta" da empresa.

Conclui-se de sua análise:

- Variáveis do ambiente de trabalho que mais influenciaram o entrevistado a desenvolver suas competências: negociação com fornecedores e contato direto com o público.

- Habilidades já existentes e relação com as competências gerenciais: disciplina, que vai ao encontro das competências de saber comprometer-se e saber assumir responsabilidades (FLEURY; FLEURY, 2001, p. 22).

- Habilidades que desenvolveu no desempenho da função relacionadas com as competências gerenciais: poder de negociação e relacionamento com o público, relacionadas às competências de saber comunicar e ter visão estratégica, coordenação de escalas dos colegas, saber mobilizar (FLEURY; FLEURY, 2001, p. 22).

\subsection{Entrevistado B}

À frente de duas empresas atacadistas dos setores de alimentação, de higiene e de limpeza atua fornecendo produtos para mercearias e até para supermercados. Na entrevista declarou que sua escolaridade formal o ajudou no momento de abrir o negócio: "com o conhecimento que eu tinha antes, me ajudou muito para começar”. O entrevistado afirma que é preciso sempre desenvolver novas habilidades.

Em torno desse aspecto necessitou adotar novas tecnologias:

Tive que me adaptar. Tive que me adaptar, sempre tem que estar inovando, e havendo uma nova tecnologia é... e também por imposição do governo, né? Quanto ao uso da informática, hoje, por exemplo, é tudo computadorizado, isso daí é mais por imposição do mercado, do mercado e do governo, então para não ficar para trás tem que ir se adaptando a tudo isso.

Sem dúvidas, o advento dos sistemas informatizados e mais recentemente, a grande imersão de empresas no comércio eletrônico provocaram mudanças nas relações de trabalho e, consequentemente, nas habilidades e competências de gestores e demais colaboradores. É preciso identificar as competências requeridas no cotidiano de seu trabalho e no âmbito da sua gestão (PAIVA et al., 2014), em que essas competências são imprescindíveis para a organização, pois possibilitam o planejamento estratégico para a tomada de decisões, a fim de atingir resultados esperados ao desempenho diante da competitividade contemporânea no contexto organizacional (SANTOS; DOS SANTOS; BELLUZZO, 2016).

Aprendeu a se adaptar às mudanças tecnológicas e aos processos de trabalho. Em sua percepção, o estudo formal, especialmente, específico faz falta em alguns momentos do trabalho, mas o aprendizado acontece todos os dias. Há um constante processo de construção e aperfeiçoamento de conhecimentos adquiridos diante da dinâmica das situações no trabalho.

Conclui-se de sua análise:

- Variáveis do ambiente de trabalho que mais influenciaram a desenvolver suas competências: mercado e governo em sua imposição pela busca por novas tecnologias, e contato com clientes e fornecedores.

- Habilidades já existentes e relação com as competências gerenciais: empreendedorismo e saber agir (FLEURY; FLEURY, 2001, p. 22).

- Habilidades que desenvolveu no desempenho da função relacionadas com as competências gerenciais: visão de mercado, ter visão estratégica, capacidade de adaptação, saber aprender; capacidade gerencial, saber mobilizar, capacidade de negociação, saber comunicar (FLEURY; FLEURY, 2001, p. 22).

\subsection{Entrevistada C}

Gerente em uma loja de comércio varejista de calçados e acessórios atua na coordenação de cinco vendedores e é subordinada à chefia, executando a mediação no relacionamento destes. Possui conhecimento de todas as áreas da empresa, mas com mais profundidade nas que trabalha.

Possui formação em Magistério e, segundo ela, isso the serviu de "âncora" no sentido de relacionamento interpessoal. Apoia os vendedores no relacionamento com os clientes e contribui com informações para a realização das compras pela chefia. A formação educacional contribui, pois fornece as ferramentas e base conceitual para a execução das tarefas diárias e resolução de problemas, mas a abordagem de Le Boterf (1995) ficaria incompleta se não considerasse a experiência profissional. É ela que gera na mente dos indivíduos a noção real de como resolver situações que, embora inéditas a cada dia, guardam certas semelhanças com outras passadas, o que 
dá respaldo à tomada de decisões no sentido de que se deu certo antes, poderá dar agora. É interessante citar que Fleury e Fleury (2004) explanam a abordagem de Le Boterf (1995), que situa competências como o resultado do cruzamento de três eixos: pessoa (biografia e socialização), formação educacional e experiência profissional. A pessoa, em relação à biografia e socialização no sentido de que o indivíduo carrega características de sua personalidade consequentes de fatos passados e que influenciarão em seu trabalho, especialmente, em aspectos não operacionais, mas no trabalhar com pessoas e/ou equipes, por exemplo.

A entrevistada acredita que a fonte de motivação pessoal é inteiramente interna e usa exemplos do esporte para incentivar sua equipe. Acerca do negócio, pensa em boas ideias para esse e compartilha com seus superiores.

Quando entrou na empresa se sentiu muito desafiada com a missão de usar computadores, mas buscou qualificação e se profissionalizou. Essa dificuldade foi superada, mas destaca que foi preciso aprender a lidar com novas tecnologias. Outra área que foi novidade foi a coordenação de um grupo, pois com isso precisou aprender a trabalhar com pessoas: “...tudo isso tinha que ter noção de computador e de como lidar com pessoas também...".

Conclui-se de sua análise:

- Variáveis do ambiente de trabalho que mais influenciaram a desenvolver suas competências: novidades tecnológicas e trabalho com pessoas.

- Habilidades já existentes e relação com as competências gerenciais: falar em público, base do Magistério, saber agir (FLEURY; FLEURY, 2001, p. 22).

- Habilidades que desenvolveu no desempenho da função relacionadas com as competências gerenciais: mediação na relação interpessoal, saber comunicar, coordenação das tarefas da equipe, saber mobilizar, raciocínio sobre a competitividade do negócio, ter visão estratégica (FLEURY; FLEURY, 2001, p. 22).

\subsection{Entrevistada D}

Coordena uma equipe de vinte e seis pessoas, entre esses há os vendedores. Atua na função há dois anos e considera importante que suas decisões estejam em comum acordo com sua chefia. A entrevistada também está na mediação entre equipe e diretoria.

Seu foco é na capacidade de iniciativa da equipe, pois percebe quando alguém na equipe tem aptidões para alguma determinada tarefa através da observação de seu comportamento e resultados: "Quando ele tem algo a mais no seu diferencial. Faz o algo a mais, então a gente sabe que tem aptidões para fazer o diferencial dentro da empresa.".

Seu contato com os fornecedores é direto, pois atua na compra e escolha de mercadoria e seu contato com os clientes é no auxílio aos vendedores, no sentido de criar e manter uma relação com eles.

É interessante destacar que ela considera sua educação formal como o que lhe deu "bagagem" e "amplitude" no trabalho, e inclui cursos profissionalizantes que fez na área de gestão, mas conta que precisou desenvolver novas habilidades, principalmente, porque iniciou no cargo de vendedora e foi ao passar do tempo, trabalhando em vários setores de tal forma que:

[...] como eu tinha conhecimento da empresa, conhecimento do produto, participava das compras, como diz a gente veste a camiseta da empresa, se dedica, se desenvolve, é de confiança, é aquela coisa, né? É meio regional, você passa a ter oportunidades e eu tive essa oportunidade, mas não me contentei só com isso, né? Procurei buscar mais [...].

Para Comin et al. (2017, p. 245): "no contexto organizacional em que a mudança é uma constante, o processo de gerenciar exige atualização permanente dos profissionais".

A oportunidade de crescer profissionalmente foi aproveitada, então, seu cargo gerencial lhe proporcionou uma nova realidade: está agora à frente de um grupo de pessoas, precisa se manter atenta ao mercado "[...] porque o comércio está aí, a competição está aí, a gente tem que estar sempre preparado trazendo algo a mais pra que ele desenvolva”.

Conclui-se de sua análise:

- Variáveis do ambiente de trabalho que mais influenciaram a desenvolver suas competências: oportunidades de crescer através da obtenção de mais conhecimento e a competição relativa do setor de comércio.

- Habilidades já existentes e relação com as competências gerenciais: conhecimento acerca de gestão e liderança, saber mobilizar e tenacidade na busca por novas formas de trabalho, saber assumir responsabilidades (FLEURY; FLEURY, 2001, p.22).

- Habilidades que desenvolveu no desempenho da função relacionadas com as competências gerenciais: capacidade de aprender processos novos de trabalho, saber aprender, capacidade de liderar pessoas, saber comunicar e visão do mercado, ter visão estratégica (FLEURY; FLEURY, 2001, p.22).

\subsection{Entrevistado E}

Sócio proprietário de uma empresa de distribuição de gases atmosféricos e industriais, atua há quatorze anos na área. Subentende-se que conhece todas as áreas da empresa, pois é seu fundador e em relação aos clientes atua em basicamente duas frentes: comercialização e assistência técnica. Sentese gratificado em seu trabalho, especialmente, em relação a suprir gases usados na medicina, o que tem ajudado a salvar vidas.

Quando perguntado se sua educação formal o ajuda em seu trabalho ele responde:

Fundamentalmente, porque toda a atividade está baseada num conhecimento técnico, embora exista um conhecimento tácito com relação ao mercado, e com relação ao relacionamento interpessoal, mas o conhecimento técnico dos produtos, do setor e das aplicações, diversas aplicações dos produtos, na atividade industrial e medicinal, são as áreas que nós atuamos, é fundamental, então a formação com certeza foi a base de tudo.

Esta formação que lhe deu base foi sua educação formal, incluindo um curso no exterior junto ao fabricante para aprender sobre o setor. $\mathrm{O}$ conhecimento tácito, referente ao 
mercado e relacionamento interpessoal é revelado como algo que, por um tempo, emanava exclusivamente de sua percepção até ser enriquecido com o teor de seu Curso Superior, que está em andamento. O primeiro passo quando decidiu abrir o negócio foi se inteirar acerca do setor e percebe, atualmente, que o mercado está cada vez mais aberto a novos concorrentes.

Conclui-se de sua análise:

- Variáveis do ambiente de trabalho que mais influenciaram a desenvolver suas competências: concorrência e configuração geral do mercado.

- Habilidades já existentes e relação com as competências gerenciais: capacidade empreendedora e percepção de nichos de mercado, "ter visão estratégica", "saber agir" e "saber assumir responsabilidades" (FLEURY; FLEURY, 2001, p.22).

- Habilidades que desenvolveu no desempenho da função relacionadas com as competências gerenciais: buscou conhecimento técnico e gerencial "saber aprender", e desenvolveu um relacionamento com os clientes e fornecedores, "saber comunicar" (FLEURY; FLEURY, 2001, p.22).

\subsection{Entrevistada F}

Coordena os trabalhos e uma equipe de três vendedores em uma empresa de comércio varejista de confecções masculinas e femininas há um ano e meio. Na empresa, já trabalha há dez anos, passando também por vários setores e adquirindo, consequentemente, um vasto conhecimento do negócio. Valoriza a empresa pelo tempo em que está se sentindo responsável "porque é como se ela fosse minha", ela também testemunhou muitos avanços tecnológicos nesse período. Percebe quando alguém tem aptidões para alguma determinada tarefa pela observação e usa o diálogo como ferramenta para gerenciar sua equipe.

Por possuir formação em Magistério, atribui a esse curso a capacidade que possui de trabalhar com o público, mas relata que precisou desenvolver outras habilidades: "com certeza, porque a gente lida com pessoas...então... todo mundo pensa diferente, jamais uma pessoa vai pensar como tu, então... eu acho que o gerente ele está para isso, para balançar, para equilibrar...". Percebe o setor como extremamente competitivo e dinâmico, "no comércio é tudo muito rápido" e seu papel é dar apoio aos vendedores, pois "são eles que fazem fluir". Há uma relação entre o que o indivíduo traz como bagagem e a prática nas situações do trabalho. Ao adotar uma definição para competência, utiliza-se Fleury e Fleury (2000, p. 21): "Definimos, assim, competência: um saber agir responsável e reconhecido, que implica mobilizar, integrar, transferir conhecimentos, recursos, habilidades, que agreguem valor econômico à organização e valor social ao indivíduo". Esta forma de ver as competências, de acordo com Fleck (2008), enfatiza ação e resultados.

Conclui-se de sua análise:

- Variáveis do ambiente de trabalho que mais influenciaram a entrevistada a desenvolver suas competências: dinamicidade do mercado e coordenação de pessoas.

- Habilidades já existentes e relação com as competências gerenciais: trabalhar em contato com o público em função do curso de Magistério, "saber agir" (FLEURY; FLEURY, 2001, p.22).

- Habilidades que desenvolveu no desempenho da função relacionadas com as competências gerenciais: coordenação do grupo, "saber comunicar", "saber mobilizar", capacidade de aprender novos processos, "saber aprender"; responsabilidade pelo trabalho, "saber assumir responsabilidades", "saber comprometer-se" (FLEURY; FLEURY, 2001, p.22).

\subsection{Entrevistada G}

Atua no auxílio ao proprietário na frente de duas lojas do setor de comércio varejista, viveu o crescimento do negócio como um todo, incluindo avanços tecnológicos, contratação de mais pessoal e avanço no mercado. Motiva-se porque gosta do que faz e conhece todas as áreas da empresa, embora atue mais na parte de compras e estratégia de vendas.

Relaciona-se diretamente com os fornecedores e sempre interage com os clientes quando está junto com os vendedores. Segundo ela, os clientes estão cada vez mais informados acerca do setor e isso pode ser proveitoso quando se consegue descobrir o que eles procuram.

Considera importante seu conhecimento formal, especialmente, por sua formação ser na área de vendas e marketing, pois isto lhe garantiu uma "visão mais técnica" e bagagem para pôr muitas ideias em prática. Quanto a desenvolver novas habilidades destacou: "Principalmente interpessoais..." pois declara que o dia a dia de trabalho absorve tanto os profissionais que essa parte corre o risco de ficar esquecida.

Outra área que precisou desenvolver foi quanto a delegar responsabilidades para outras pessoas envolvidas na empresa, pois à medida que o negócio crescia, foi necessário para viabilizar o fluxo de trabalho. Não basta apenas "saber", pois pode ocorrer o fato de o profissional ter excelente currículo e ser insuficiente no momento de resolver questões práticas, inclusive as que envolvem o inesperado, o imprevisto. É preciso "saber fazer", ou seja, as habilidades são como ferramentas na mão da pessoa, do qual desenvolve ela mesma, caminhos para a solução de problemas e resolução de tarefas, resultando em um desempenho satisfatório no trabalho. Sendo assim, Fleck (2008, p. 26) sintetiza a dinamicidade das competências gerenciais:

Em síntese, as competências gerenciais partem de uma rede de fatores e influências, como a formação da pessoa, o meio em que ela conviveu durante o seu crescimento e que afetou o meio em que convive depois de adulta; além é claro das políticas da organização onde trabalha e na qual poderá ou não ter suas competências utilizadas e desenvolvidas (FLECK, 2008, p. 26).

Esses fatores e influências que formam essa rede são de suma importância, não como uma base estática em que descansa o perfil do profissional, mas como elementos dinâmicos de alimentação das competências gerenciais. São semelhantes aos três eixos de Le Boterf (1995): pessoa, 
formação educacional e experiência profissional, mas são compostos também pelas políticas organizacionais e, consequentemente, pelo ambiente como um todo, pois esses geram pressões que exigem o desenvolvimento ou não de competências, e isso ocorre também no nível gerencial.

Conclui-se de sua análise:

- Variáveis do ambiente de trabalho que mais influenciaram a desenvolver suas competências: crescimento da empresa, aumento do número de pessoas na equipe.

- Habilidades já existentes e relação com as competências gerenciais: conhecimento da formatação do mercado em função do Curso Superior em Administração, "ter visão estratégica", "saber agir" e capacidade empreendedora, "saber assumir responsabilidades", "saber comprometerse" (FLEURY; FLEURY, 2001, p.22).

- Habilidades que desenvolveu no desempenho da função relacionadas com as competências gerenciais: relacionamento interpessoal, "saber comunicar"; capacidade de delegar funções a seus subordinados, "saber mobilizar", "saber aprender" (FLEURY; FLEURY, 2001, p. 22).

\subsection{Entrevistada $\mathrm{H}$}

Depois de uma experiência de dezesseis anos no Magistério, a entrevistada está tendo há um ano e meio a vivência de coordenar os trabalhos em uma loja do setor de comércio de confecções infantis, o qual considera bastante competitivo. Justamente o Magistério lhe proporcionou maior segurança para trabalhar em contato com crianças e com as variáveis que compõem o universo infantil.

Esta experiência no comércio lhe colocou na função gerencial, coordenando processos normais de uma loja. Possui conhecimento de todas as áreas da empresa, faz a relação entre a funcionária e a chefia e no relacionamento com os fornecedores executa as diretrizes da proprietária.

No relacionamento com os clientes atua diretamente no atendimento também, sendo essa a área do qual mais precisou desenvolver, pois segundo ela, o ato de vender envolve variáveis que ela está aprendendo a lidar: “Atender o público, vender, foi um aprendizado".

É motivada pela vontade de que a empresa cresça e seja cada vez mais conhecida, sente-se parte disso e incentiva as pessoas com que trabalha no mesmo sentido, com otimismo. Para Comin et al. (2017, p.245): “a gestão de pessoas propicia para o alinhamento estratégico dos interesses entre empresas e funcionários".

Conclui-se de sua análise:

- Variáveis do ambiente de trabalho que mais influenciaram a desenvolver suas competências: negociação com clientes, concorrência do setor comercial e prazos.

- Habilidades já existentes e relação com as competências gerenciais: trato com crianças em função da experiência de lecionar para esta faixa etária, "saber comunicar"; capacidade empreendedora por aceitar o desafio de ingressar no setor comercial, "saber assumir responsabilidades", "saber agir", "saber comprometerse" (FLEURY; FLEURY, 2001, p. 22).

- Habilidades que desenvolveu no desempenho da função relacionadas com as competências gerenciais: coordenação dos processos da loja, "saber mobilizar", "saber aprender", capacidade de negociação, "ter visão estratégica” (FLEURY; FLEURY, 2001, p.22).

Através das entrevistas foi possível verificar que para todos os indivíduos participantes se encontram variáveis relacionadas ao ambiente que contribuem para o desenvolvimento de suas competências, algumas já existentes por conta de formação anterior ou perfil profissional e outras que foram desenvolvidas no desempenho da função. Demonstrando que o modelo apresentado por Fleury e Fleury (2001) e escolhido para o desenvolvimento da pesquisa foi adequado para mapear competências gerenciais dos indivíduos pesquisados, e permitiu verificar que o que mais é demandado nos cargos e empresas, nas quais estas pessoas atuam se relaciona com saberes que foram desenvolvidos em função do ambiente de trabalho, conforme pode ser verificado no Quadro 2.

Quadro 2 - Síntese das competências gerenciais dos entrevistados

\begin{tabular}{|c|c|c|c|c|c|c|c|}
\hline 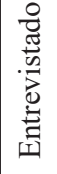 & Saber agir & $\begin{array}{c}\text { Saber } \\
\text { mobilizar }\end{array}$ & $\begin{array}{c}\text { Saber } \\
\text { comunicar }\end{array}$ & $\begin{array}{c}\text { Saber } \\
\text { aprender }\end{array}$ & $\begin{array}{c}\text { Saber } \\
\text { comprometer-se }\end{array}$ & $\begin{array}{c}\text { Saber } \\
\text { Assumir } \\
\text { Responsabilidades }\end{array}$ & $\begin{array}{c}\text { Ter } \\
\text { Visão } \\
\text { Estratégica }\end{array}$ \\
\hline A & - & Ambiente & Ambiente & - & Existente & Existente & Ambiente \\
\hline $\mathrm{B}$ & Existente & Ambiente & Ambiente & Ambiente & - & - & Ambiente \\
\hline $\mathrm{C}$ & Existente & Ambiente & Ambiente & - & - & - & Ambiente \\
\hline $\mathrm{D}$ & - & Existente & Ambiente & Ambiente & - & Existente & Ambiente \\
\hline $\mathrm{E}$ & Existente & - & Ambiente & Ambiente & - & Existente & Existente \\
\hline $\mathrm{F}$ & Existente & Ambiente & Ambiente & Ambiente & Ambiente & Ambiente & - \\
\hline $\mathrm{G}$ & Existente & Ambiente & Ambiente & Ambiente & Existente & Existente & Existente \\
\hline $\mathrm{H}$ & Existente & Ambiente & Existente & Ambiente & Existente & Existente & Ambiente \\
\hline
\end{tabular}

Fonte: dados da pesquisa.

Dois dos entrevistados, E e G, já demonstravam possuir visão estratégica do mercado antes de abrir e iniciar no negócio, o que lhes impulsionou a agir.

As competências de "saber comunicar" e "saber aprender" 
aparecem como variáveis desenvolvidas pelo ambiente em todos os entrevistados, ao contrário da variável de "saber agir", que se mostrou como uma competência já existente.

Quanto a "saber comunicar", esta competência aparece em todos os entrevistados. Considerando experiência anterior, os que atuaram no Magistério deram destaque a se sentirem mais seguros nesse requisito. As variáveis que mais impulsionaram os entrevistados foram a concorrência dos setores em que esses estão envolvidos e as novas atribuições de seus cargos, com destaque para a liderança de pessoas e contato com clientes.

Considerar o aumento da complexidade das situações é fundamental para associar os conhecimentos adquiridos com realidade, e a competência é vista como transformar tais conhecimentos em atitudes reais. Apoiar-se neles e transformá-los, além da relação prática do indivíduo com a situação profissional, são aspectos que envolvem certo grau de autonomia, na prática, tomada de decisões. É a maneira como a pessoa enfrenta as situações: tomar iniciativa, assumir responsabilidades. Em síntese, é o que vai compor o desempenho do profissional.

Os resultados encontrados permitem reforçar os achados da literatura, demonstrando que há competências gerenciais que figuram mais como natas e/ou presentes nos gestores desde antes de assumirem a atual posição no trabalho, e outras, em contrapartida, que aparecem nitidamente como desenvolvidas durante o desempenhar da função gerencial.

Entre as competências gerenciais que mais aparecem entre as já existentes se tem a de "Saber agir: saber o que e por que faz. Saber julgar, escolher, decidir”. A causa provável é de que todos os entrevistados eram cientes de que assumiriam riscos e responsabilidades ao abrir um novo negócio ou assumir uma função de gestão, o que corrobora para outra competência latente, a de "Saber assumir responsabilidades: ser responsável, assumindo os riscos e as consequências de suas ações, e ser, por isso, reconhecido" (FLEURY; FLEURY, 2001, p.22).

Em relação às competências desenvolvidas em função do ambiente, "Saber comunicar" é a mais observada na maioria dos entrevistados, por necessitarem se relacionar com a equipe de trabalho, fornecedores e clientes, esta competência inclui "Compreender, processar, transmitir informações e conhecimentos, assegurando o entendimento da mensagem pelos outros" (FLEURY; FLEURY, 2001, p. 22) sendo, portanto, fundamental para o andamento do trabalho, pois todos, de uma maneira ou de outra, dependem da interação com outras pessoas, especialmente, porque são todos do setor de serviços. As competências que aparecem logo após em importância são "saber mobilizar" e "ter visão estratégica", em que a primeira envolve variáveis internas à empresa, pois compreende: "saber mobilizar recursos de pessoas, financeiros, materiais, criando sinergia entre eles " ((FLEURY; FLEURY, 2001, p.22). Estas atribuições são apresentadas pela primeira vez para a maioria dos entrevistados, quando assumem a atual posição.

\section{Conclusão}

A natureza de cada uma das competências do profissional do modelo teórico adotado envolve aspectos bastante práticos, o que facilmente leva a entender o que mais de um entrevistado expôs: o aprendizado é todos os dias. A partir dos resultados obtidos se pode afirmar que os gestores são impulsionados a desenvolverem suas competências de acordo com as exigências do ambiente de trabalho, principalmente, competências relacionadas ao relacionamento interpessoal, mobilização de recursos e percepção de mercado. O que leva a concluir que as pessoas são plenamente capazes de desenvolver habilmente competências gerenciais, desde que entre suas características pessoais esteja um perfil voltado para capacidade de assumir responsabilidade e lidar com as consequências das demandas do cargo; características que podem ser inerentes a qualquer ser humano. O processo de gestão é dinâmico e assumir um cargo de gestão parece ter relação direta com o interesse por esse tipo de responsabilidade profissional.

Os dados levantados por este estudo reforçam o que a teoria já indicava, no entanto, não permitem generalizações sobre os achados aqui evidenciados, nem mesmo sobre a efetividade da teoria em todo e qualquer cenário a ser pesquisado. Assim sendo, novas pesquisas podem ser realizadas no sentido de reforçar estes resultados e os bons argumentos no que se refere à pesquisa sobre competências gerenciais, bem como investigar outras capacidades dos gestores, adotando também outros critérios para a seleção de respondentes e a replicação da pesquisa em outros setores da economia.

\section{Referências}

BITENCOURT, C. C. A Gestão de competências gerenciais e a contribuição da aprendizagem organizacional. RAE, v.44, n.1, p.58-69, 2004.

BOYATZIS, R. E. The competent management: a model for effective performance. New York: John Wiley, 1982.

BRAGA, A.C.; RIGATTI, D. International conurbations along Brazil-Uruguay border: how ambiguity drives spatial patterns and social exchange. Stockholm: KHT, 2009.

BRANDÃO H.P.; BORGES-ANDRADE, J.E. Causas e Efeitos da Expressão de Competências no Trabalho. Rev. Adm. Mackenzie, v.8, n.3, p.32-49, 2007.

BRANDÃO, H. P. et al. Gestão de desempenho por competências: integrando a avaliação 360 graus, o balanced scorecard e a gestão por competências. Rev. Adm. Pública, v.42, n.5, p.875-898, 2008.

CARBONE, P.P. et al. Gestão por competências e gestão do conhecimento. Rio de Janeiro: Fundação Getúlio Vargas, 2005.

COCKERILL, T. The kind of competence for rapid change. In: MABEY, C.; ILES, P. (Org.). Managing learning. London: Routledge, 1994. p.70-76.

COMIN, L. C. et al. Perspectivas em Gestão \& Conhecimento, v.7, n.1, p.232-247, 2017.

CRESWELL, J. W. Investigação qualitativa e projeto de pesquisa: escolhendo entre cinco abordagens. Porto Alegre: Penso, 2014.

DUTRA, J. S. et al. Gestão por Competências. São Paulo: Gente, 2001. 
DUTRA, J. S. Competências: conceitos e instrumentos para a gestão de pessoas na empresa moderna. São Paulo: Atlas, 2004.

FLECK, C. F. Inteligências múltiplas e comportamento gerencial: estudo da relação entre os perfis dos coordenadores de Pós-Graduação das Universidades Federais do RS. Santa Maria: Universidade Federal de Santa Maria, 2008.

FLEURY, M.T.L.; FLEURY, A. Construindo o Conceito de Competência. RAC, v.5, p. 183-196, 2001.

FLEURY, M.T.L.; FLEURY, A. Alinhando estratégia e competências. $R A E$, v. 44, n. 1, p. 44-57, 2004.

GONCZI, A. Competency-based learning: a dubious past: an assured future? In: BOUD, D.; GARRICK, J. (Org.). Understanding learning at work. London: Routledge, 1999. p.180-194)

HAIR Jr., J. F. et al. Fundamentos de métodos de pesquisa em administração. Porto Alegre: Bookman, 2005.

LE BOTERF, G. De la conpeténce. Essai sur un attacteurétrange. Paris: Les Editions D’organizations, Quatriémetirage, 1995.
MCCLELLAND, D. Testing for competence rather than for "intelligence". Am. Psychol., v.28, n.1, p.1-14, 1973.

OLIVEIRA, M.M. Como fazer pesquisa qualitativa. Petrópolis: Vozes, 2007.

PAIVA, K.C.M. et al. Competências docentes ideais e reais em educação a distância no curso de administração: um estudo em uma instituição brasileira. Tourism \& Management Studies, v.10, p.121-128, 2014.

SALLES, M.; VILLARDI, B. O desenvolvimento de competências gerenciais na prática dos gestores no contexto de uma IFES centenária. $R S P$, v.68, n.2, p.467-492, 2017.

SANTOS, V.C.B.; DOS SANTOS, C.A.; BELLUZZO, R.C.B. A competência em informação em articulação com a inteligência competitiva no apoio ao alinhamento estratégico das informações nas organizações. Perspectivas em Gestão \& Conhecimento, v. 6, n. 1, p. 45-60, 2016.

SEVERINO, A. J. Metodologia do trabalho cientifico. São Paulo: Cortez, 2017.

ZARIFIAN, P. Gestão de Competências. São Paulo: Atlas, 2001. 